\title{
KEHILANGAN $\mathrm{H}_{2} \mathrm{O}$ SELAMA REAKSI PELINDIAN MINERAL ZIRCON DENGAN NaOH DI DALAM FURNACE
}

\section{LOSS OF $\mathrm{H}_{2} \mathrm{O}$ DURING THE LEACHING REACTION OF ZIRCON MINERALS WITH NAOH IN FURNACE}

\author{
Triyono, Muzakky \\ PSTA - BATAN, Jl. Babarsari Kotak Pos 6101 ykbb Yogyakarta 55281 \\ E-mail: triyono793@gmail.com
}

Diterima 19 September 2018, diterima dalam bentuk perbaikan 21 Pebruari 2019, disetujui 4 April 2019

\begin{abstract}
ABSTRAK
KEHILANGAN $\mathrm{H}_{2} \mathrm{O}$ SELAMA REAKSI PELINDIAN MINERAL ZIRCON DENGAN NaOH DI DALAM FURNACE. Telah dilakukan prediksi jumlah kehilangan $\mathrm{H}_{2} \mathrm{O}$ selama proses peleburan mineral zirkon dengan $\mathrm{NaOH}$ di dalam furnace. Proses awal pemurnian zirkonium dimulai dari pelindian mineral zirkon dengan $\mathrm{NaOH}$. Selama proses peleburan akan dikeluarkan $\mathrm{H}_{2} \mathrm{O}$ yang diperkirakan akan membawa $\mathrm{Rn}-222$ dan Rn-220 yang berbahaya bagi pekerja radiasi. Maka tujuan dari pelitian ini adalah melakukan prediksi jumlah kehilangan $\mathrm{H}_{2} \mathrm{O}$ pada reaksi pelindian mineral zirkon dengan $\mathrm{NaOH}$ di dalam furnace dan keluar ke udara. Kehilangan $\mathrm{H}_{2} \mathrm{O}$ dihitung berdasarkan mol sebelum reaksi peleburan dikurangi dengan sesudah reaksi peleburan. Hasil pengamatan menunjukkan bahwa semakin tinggi temperatur dan lama waktu kontak, kehilangan mole $\mathrm{H}_{2} \mathrm{O}$ akan semakin besar. Besarnya kehilangan mole $\mathrm{H}_{2} \mathrm{O}$ akan dipengaruhi oleh mole rasio $\mathrm{ZrSiO}_{4} / \mathrm{NaOH}$. Kecuali pada mol rasio $\mathrm{ZrSiO} 4 / \mathrm{NaOH}$ (1:4), mol kehilangan $\mathrm{H}_{2} \mathrm{O}$ berharga sama dengan mol rasio $\mathrm{ZrSiO}_{4} / \mathrm{NaOH}$ (1:2). Kehilangan mol $\mathrm{H}_{2} \mathrm{O}$ dicapai pada mol rasio $\mathrm{ZrSiO} / \mathrm{NaOH}$ (1:8), pada temperatur $950^{\circ} \mathrm{C}$ dan waktu kontak 60 menit sebesar 0,024 mole/gr. Pada kondisi tersebut sisa fase kristal $\mathrm{ZrSiO}_{4}$ tidak terbentuk, tetapi sampel mengandung sisa $\mathrm{NaOH}$ yang tidak bereaksi dan bersifat pasta.
\end{abstract}

Kata kunci : mol rasio $\mathrm{ZrSiO} / \mathrm{NaOH}$, mineral zirkon, peleburan

\begin{abstract}
LOSS OF $\mathrm{H}_{2} \mathrm{O}$ DURING THE LEACHING REACTION OF ZIRCON MINERALS WITH NaOH IN FURNACE. It has been predicted the amount of $\mathrm{H}_{2} \mathrm{O}$ loss during the leaching reaction of zircon mineral with $\mathrm{NaOH}$ in the furnace. The initial process of zirconium purification begins with the leaching of zirconium minerals with $\mathrm{NaOH}$. During the leaching process, $\mathrm{H}_{2} \mathrm{O}$ is released which is expected to carry over Rn-222 and Rn-220 which are harmful to the radiation workers. So the objective of this investigation is to predict the amount of $\mathrm{H}_{2} \mathrm{O}$ loss in zircon mineral reactions with $\mathrm{NaOH}$ in the furnace and exit to the air. Loss ratio of $\mathrm{H}_{2} \mathrm{O}$ was calculated based on the mole before the reaction minus by the mole after the reaction. The results show that the increased both temperature and contact time, will be increased of loss moles ratio of $\mathrm{H}_{2} \mathrm{O}$ The amount of $\mathrm{H}_{2} \mathrm{O}$ mole loss will be affected by the mole ratio of $\mathrm{ZrSiO}_{4} / \mathrm{NaOH}$. Except for the mole ratio $\mathrm{ZrSiO}_{4} / \mathrm{NaOH}$ (1:4), losses of $\mathrm{H}_{2} \mathrm{O}$ mole value was the same as the mole ratio of $\mathrm{ZrSiO}_{4} / \mathrm{NaOH}$ (1:2). Loss ratio of $\mathrm{H}_{2} \mathrm{O}$ mole achieved in the mole ratio of $\mathrm{ZrSiO}_{4} / \mathrm{NaOH}(1: 8)$, at $950{ }^{\circ} \mathrm{C}$ and 60 minutes contact time was 0.024 mole/g. Under those conditions the remaining phase of the $\mathrm{ZrSiO}_{4}$ crystal was not formed, but the sample contains the residue of unreacted $\mathrm{NaOH}$ and paste-containing $\mathrm{NaOH}$.
\end{abstract}

Key words: mole ratio $\mathrm{ZrSiO}_{4} / \mathrm{NaOH}$, zircon minerals, roasting

\section{PENDAHULUAN}

Dada umumnya di dalam mineral zirkon $\left(\mathrm{ZrSiO}_{4}\right)$ terkandung beberapa unsur berharga lain seperti titanium dalam mineral ilmenit $\left(\mathrm{FeTiO}_{3}\right.$ ), logam tanah jarang (LTJ) seperti ( $\mathrm{La}, \mathrm{Ce}, \mathrm{Nd}, \mathrm{Pr}, \mathrm{Sm}, \mathrm{Y}, \mathrm{Dy}, \mathrm{Tb}, \mathrm{Gd}$ ) dalam mineral monasit dan senotim yang mengandung naturally occurring radioactive materials (NORM) seperti $\mathrm{U}_{3} \mathrm{O}_{8}$ dan $\mathrm{ThO}_{2}$. Kebanyakan di dalam mineral zirkon berasosiasi dengan mineral monasit yang merupakan mineral radioaktif. Dengan demikian mineral zirkon dari Tumbang Titi Kalimantan Barat mengandung NORM sekitar 1587 
g/g [1,2]. Walaupun begitu penelitian oleh Coble [3], Boehnke [4], Danisík [5] kandungan U+Th dalam zirkon berguna untuk melacak keberadaan deposit mineral zirkon serta umur dari mineral zirkon $\left(\mathrm{ZrSiO}_{4}\right)$. Mineral tersebut merupakan sumber utama senyawa zirkonium untuk industri nuklir maupun nonnuklir. Industri tersebut menggunakan senyawa zirkonium seperti zirkonium sulfat, zirconium basic sulfat, zirconium aksiklorid, zirconium tetrahalida, zirkonium oksida yang semua itu merupakan bahan dasar pembuatan keramik, kimia, elektronik, militer dan industri lain [6,7]. Dalam indurtri nuklir zirkonium dengan kandungan Hafnium $<100 \mu \mathrm{g} / \mathrm{gr}$ yang berderajat nuklir, dipakai sebagai kelongsong bahan bakar uranium [7]. Secara alami kandungan U+Th di dalam mineral zirkon masing-masing akan meluruh menjadi anak luruhnya. Salah satu anak luruh U-238 adalah Rn-222 sedangkan Th-232 berupa Rn-220, dan masing-masing isotop tersebut berbentuk gas [8]. Walaupun berumur paruh pendek, dengan bentuk gas Rn-222 dan Rn-220 sangat mudah larut di dalam $\mathrm{H}_{2} \mathrm{O}$ [9-11]. Berdasar Gevantman [12] kelarutan Rn-222 di dalam $\mathrm{H}_{2} \mathrm{O}$ mencapai 1,288 $\times 10^{-4}$ mole/l, sementara Vogeltanz [13] telah meneliti penyakit kanker paru yang diakibatkan terpapar oleh radon.

Dalam industri pemurnian mineral zirkon sebagai bahan baku industri tersebut, harus melalui perlakuan kimia dengan kaustik soda terlebih dulu sebelum dimanfaatkan yang reaksinya $[6,7,14,15]$

$$
\mathrm{ZrSiO}_{4}+4 \mathrm{NaOH} \rightarrow \mathrm{Na}_{2} \mathrm{ZrO}_{3}+\mathrm{Na}_{2} \mathrm{SiO}_{3}+2 \mathrm{H}_{2} \mathrm{O} \uparrow .
$$

Aplikasi pada reaksi 1 tersebut dilakukan di dalam furnace pada suhu $600{ }^{\circ} \mathrm{C}[15,16]$ atau $700{ }^{\circ} \mathrm{C}[17]$ akan dihasilkan $\mathrm{H}_{2} \mathrm{O}$ yang menjadi uap dan sebagai carrier gas radon ke udara [8]. Berdasarkandata kelarutan gas radon ke dalam $\mathrm{H}_{2} \mathrm{O}$ yang terlepas dari mineral zirkon [12],serta dampaknya terkena kanker paru bagi pekerja radiasi menarik untuk diteliti [13]. Proses pelepasan radan keudara diperkirakan lewat pemanasan selama proses pengolahan alkali di dalam furnace [15]. Maka untuk keperluan proteksi radiasi diperlukan data berapa banyak $\mathrm{H}_{2} \mathrm{O}$ yang hilang selama proses reaksi tersebut berlangsung [14]. Maka tujuan dari penelitian ini adalah melakukan prediksi kehilangan $\mathrm{H}_{2} \mathrm{O}$ pada reaksi pelindian mineral zirkon dengan $\mathrm{NaOH}$ di dalam furnace dan keluar ke udara ruangan.Guna merealisasikan tujuan tersebut akan didahului kelayakan alat dengan melakukan kalibrasi kinerja furnace yang digunakan. Untuk merealisasikan tujuan tersebut dilakukan beberapa variasiseperti perbandingan molar $\mathrm{ZrSiO}_{4} / \mathrm{NaOH}$, waktu kontak dan variasi temperatur. Penelitian ini diharapkan akan melengkapi data pemurnium mineral zirkon menjadi produk industri yang komensial dan aman bagi pekerja radiasi.

\section{METODOLOGI}

\section{Bahan}

Mineral zirkon dari daerah Tumbang Titi Kalimantan Barat ukuran 100 mesh dan $\mathrm{NaOH}$ buatan E Merck

\section{Alat}

Furnace buatan Nabertherm HT 04/17 dan cawan porselin kapasitas $300 \mathrm{gr}$.

\section{Metode penelitian}

Dicampur antara mineral zirkon dengan $\mathrm{NaOH}$ ke dalam cawan porselen sedemikian rupa sehingga mempunyai perbandingan molar $1: 2$. Dimasukan cawan ke dalam furnace suhu tinggi dan dipanaskan hingga temperatur $600{ }^{\circ} \mathrm{C}$ selama 15 menit. Selanjutnya didinginkan dan ditimbang hingga berat tetap. Pekerjaan selanjutnya diulangi lagi dengan langkah berikut (1) perbandingan molar 1: 4, 1:6 dan 1;8 (2) variasi temperatur $700{ }^{\circ} \mathrm{C}, 800{ }^{\circ} \mathrm{C}$ dan $900{ }^{\circ} \mathrm{C}$, (3) waktu kontak 30 menit, 45 menit dan 60 menit. Selanjutnya masing-masing dilakukan pendinginan pada suhu kamar dan ditimbang hingga berat tetap. Kehilangan $\mathrm{H}_{2} \mathrm{O}$ selama reaksi pelindian mineral zirkon dengan $\mathrm{NaOH}$ dihitung sebagai berikut:

$$
\mathrm{H}_{2} \mathrm{O} \text { hilang = jumlah mole sebelum reaksi }(\mathrm{ZrSiO} 4+\mathrm{NaOH})-\text { jumlah mole setelah reaksi }
$$


Kehilangan $\mathrm{H}_{2} \mathrm{O}$ selama reaksi pelindian mineral zircon dengan $\mathrm{NaOH}$ di dalam furnace.

(Triyono, dkk)

\section{HASIL DAN PEMBAHASAN}

\section{Kinerja Furnace Nabertherm HT 04/ 17}

Penentuan kinerja alat dengan melakukan kalibrasi furnace dengan bagan alir sebagai berikut:

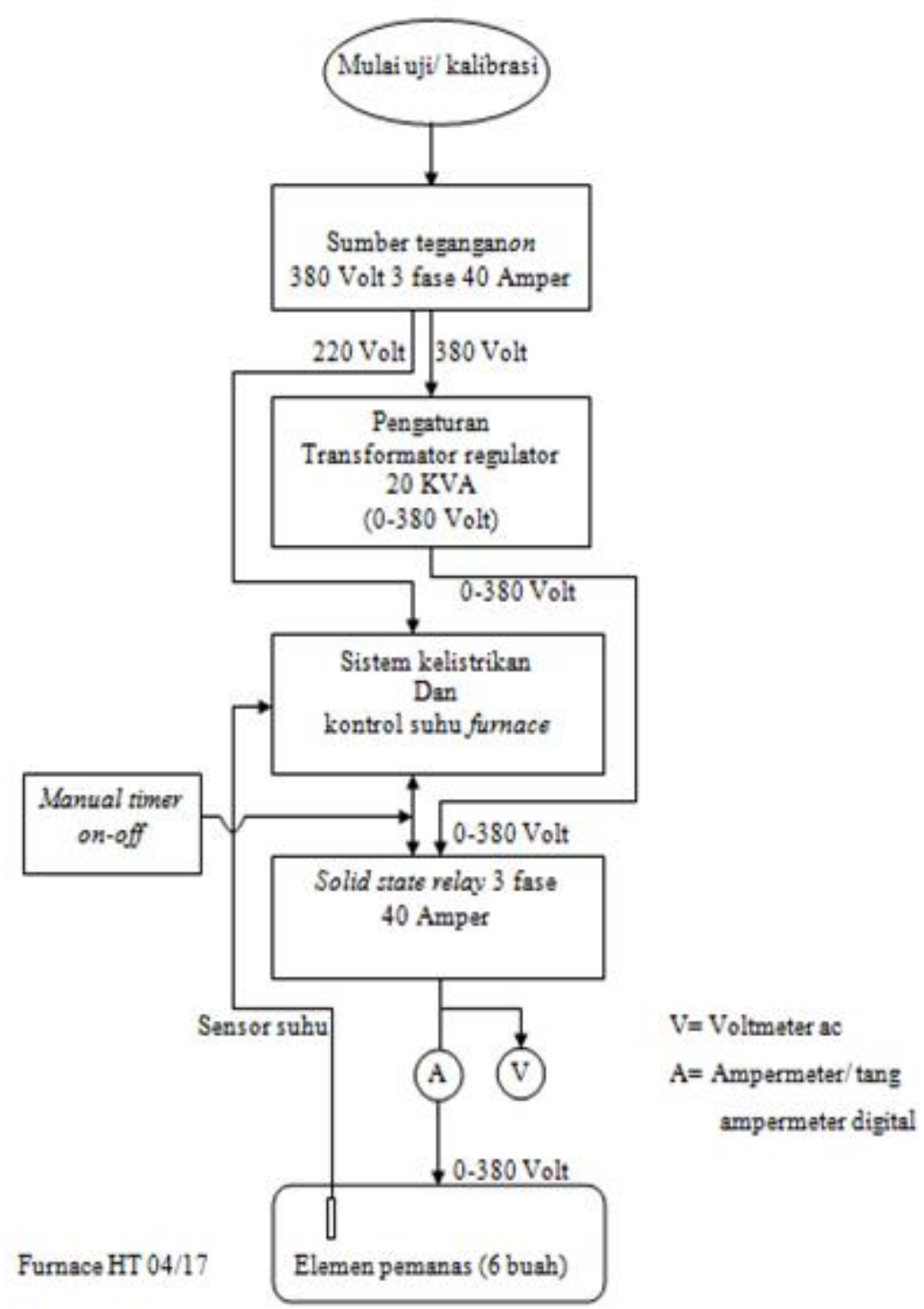

Gambar 1. Flow diagram kalibrasi/uji fungsi furnace Nabertherm HT 04/17. 


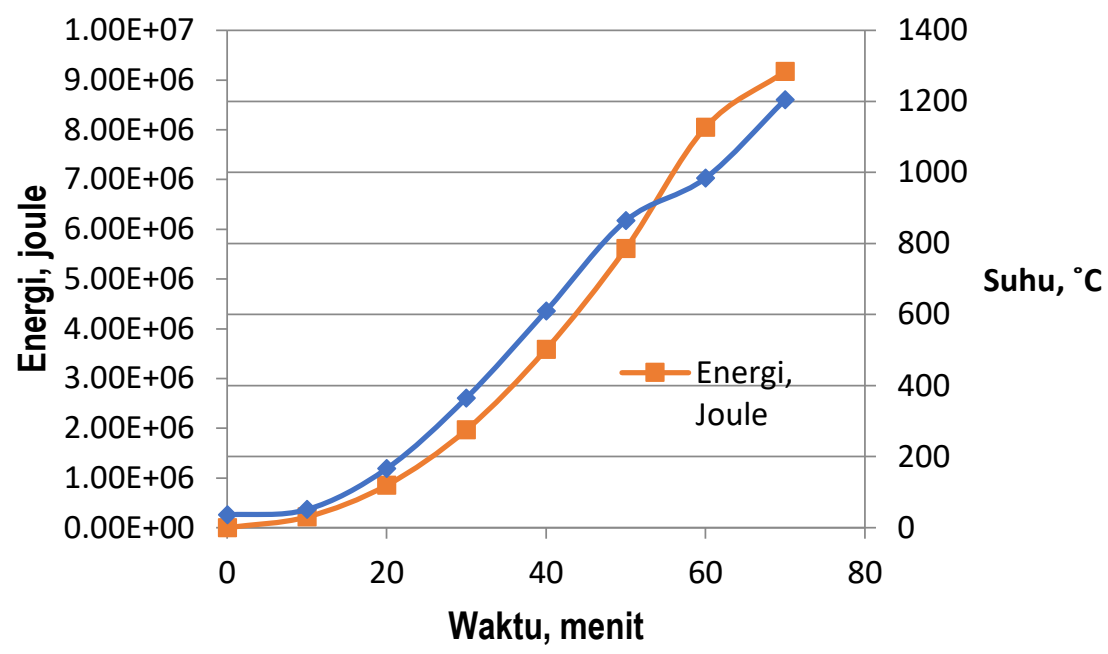

Gambar 2. Keluaran hasil kinerja furnace Nabertherm HT 04/17.

Dari Gambar 2, merupakan respon keluaran furnace dengan berdimensi volume ruang $21 \times 21 \times 15,5$ $\mathrm{cm}$. Pada Gambar 2 tampak bahwa kalibrasi suhu tertinggi dilakukan pada suhu $1205^{\circ} \mathrm{C}$, yang dicapai pada waktu operasi selama 70 menit. Sebagai perbandingan dengan alat lain, Aminhar [18] telah melakukan kalibrasi muffle furnace sebagai fungsi waktu operasi dan temperatur. Ternyata untuk mencapai suhu $1000{ }^{\circ} \mathrm{C}$ furnace Nabertherm HT 04/17 membutuhkan waktu 60 menit, sementara muffle furnace 90 menit. Perbedaan ini kemungkinan karena dimensi ruang furnace yang berbeda, maupun faktor umur heating element yang berbeda. Pada Gambar 2 tersebut ternyata dengan demensi ruang furnace $21 \times 21 \times 15,5 \mathrm{~cm}$ pada suhu $800{ }^{\circ} \mathrm{C}$, menghasilkan energi panas sebesar $5.61 \times 10^{6}$ joule. Pada keadaan energi panas tersebut mineral $\mathrm{ZrSiO}_{4}$ telah rapuh/labil secara struktur dan mudah tertreatment seperti $\mathrm{NaOH}$ [19]

\section{Kehilangan $\mathrm{H}_{2} \mathrm{O}$ selama reaksi pelindian}

Berdasarkan Biswas [14] dan Liu [6], bahwa perbandingan molar rasio $\mathrm{ZrSiO}_{4} / \mathrm{NaOH}$ akan mempengaruhi kontrol pembentukan struktur senyawa zirkonium zirkonat yang terjadi selama reaksi. Demikian pula Abdel-Rehim [20] bahwa temperatur dan waktu kontak akan mempercepat terhadap reaksi pembentukan senyawa zirkonium zirkonat yang reaksi (1). Sementara Lubbe [16] merubah perbandingan mole $\mathrm{ZrSiO}_{4} / \mathrm{NaOH}$ (1:6), sehingga dikeluarkan produk $\mathrm{H}_{2} \mathrm{O}$ yang menguap dan keluar ke udara bebas dan membawa gas radon yang beracun [8]. Pada Gambar 3 berikut dapat disajikan hasil prediksi kehilangan $\mathrm{H}_{2} \mathrm{O}$ melalui hubungan antara waktu kontak dengan kehilangan $\mathrm{H}_{2} \mathrm{O}$ di setiap perubahan temperatur pada perbandingan mole rasio $\mathrm{ZrSiO}_{4} / \mathrm{NaOH}(1: 2)$.

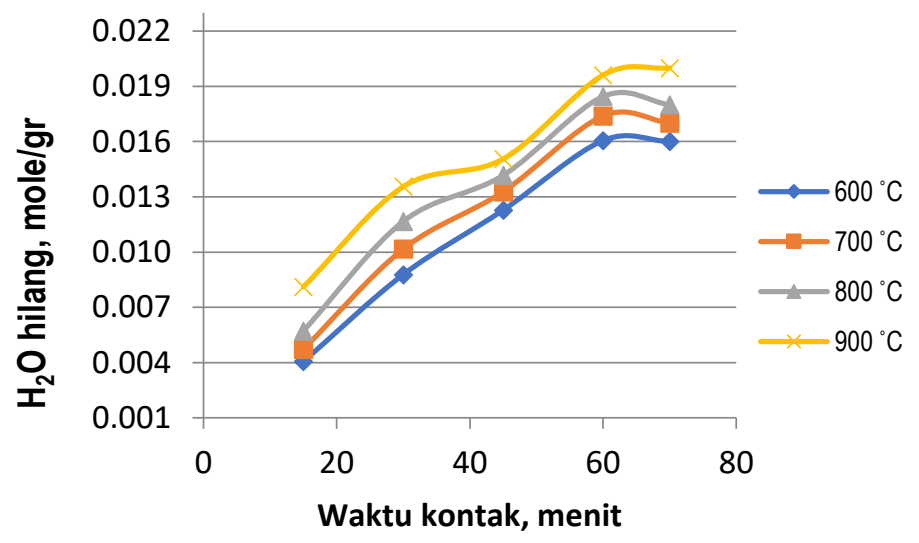

Gambar 3. Perbandingan mole rasio $\mathrm{ZrSiO}_{4} / \mathrm{NaOH}(1: 2)$ pada peleburan zirkon. 
Pada Gambar 3 dapat diperlihatkan bahwa semakin tinggi temperatur dan lama waktu kontak, kehilangan mole $\mathrm{H}_{2} \mathrm{O}$ akan semakin besar. Pada Gambar 3 bahwa kehilangan $\mathrm{H}_{2} \mathrm{O}$ tertinggi dicapai pada suhu $900{ }^{\circ} \mathrm{C}$ pada waktu kontak 60 menit dengan $0,020 \mathrm{~mol} / \mathrm{gr}$. Berdasar pengamatan hasil pada mol rasio $\mathrm{ZrSiO}_{4} / \mathrm{NaOH}(1: 2)$ akan menghasilkan produk yang berbentuk padat yang sangat sulit larut padaproses pelindian air. Berdasarkan Lubbe [16,14], reaksi pelindian dengan mole rasio $\mathrm{ZrSiO} / \mathrm{NaOH}$ (1:2) masih didominasi oleh $\mathrm{Na}_{2} \mathrm{ZrSiO}_{5}$ yang sulit larut dalam air dan tidak bisa digunakan pada proses berikutnya yang reaksinya,

$$
\mathrm{ZrSiO}_{4}+2 \mathrm{NaOH} \rightarrow \mathrm{Na}_{2} \mathrm{ZrSiO}_{5}+\mathrm{H}_{2} \mathrm{O} \uparrow
$$

Pada persamaan reaksi (3) di atas dengan sendirinya masih mengandung $\mathrm{ZrSiO}_{4}$ dan $\mathrm{NaOH}$ yang tidak bereaksi dan hanya kehilangan $\mathrm{H}_{2} \mathrm{O}$ yang menguap [15]. Ternyata pada mole rasio $\mathrm{ZrSiO} / \mathrm{NaOH}$ (1:2) prediksi kehilangan $\mathrm{H}_{2} \mathrm{O}$ paling tinggi pada waktu kontak 60 menit dengan suhu $900{ }^{\circ} \mathrm{C}$ sebesar 0,02 mole/gr.

Selanjutnya proses peleburan dinaikkan dengan $\mathrm{mol}$ rasio $\mathrm{ZrSiO}_{4} / \mathrm{NaOH}(1: 4)$, dan hasilnya dapat dilihat pada Gambar 4. Ternyata pada Gambar 4, dapat ditampilkan bahwa semakin lama waktu kontak dan semakin tinggi temperatur tampak kehilangan $\mathrm{H}_{2} \mathrm{O}$ akan semakin tinggi. Fenomena ini sesuai dengan penelitian Biswas [14], yang menyatakan bahwa semakin lama waktu kontak dan tingginya temperatur pembentukan $\mathrm{Na}_{2} \mathrm{ZrO}_{3}$ semakin tinggi

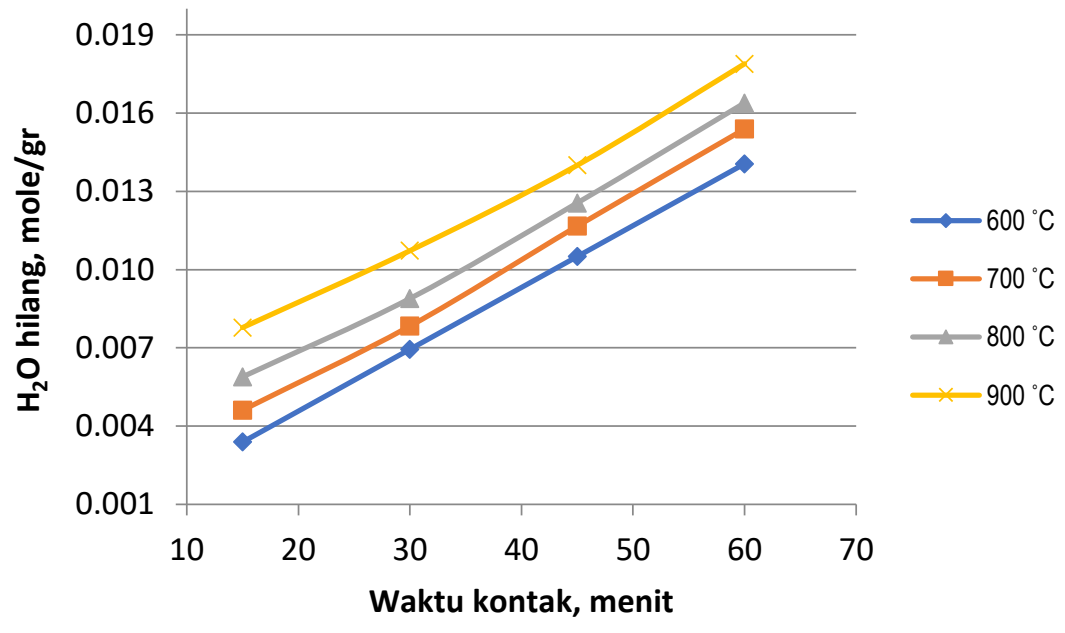

Gambar 4. Perbandingan mol rasio $\mathrm{ZrSiO}_{4} / \mathrm{NaOH}$ (1:4) pada peleburan zirkon.

Pada Gambar 4 diperlihatkan bahwa mol rasio $\mathrm{ZrSiO}_{4} / \mathrm{NaOH}(1: 4)$ diperlihatkan bahwa kehilangan $\mathrm{H}_{2} \mathrm{O}$ tertinggi dicapai pada waktu kontak 60 menit dengan temperetur $900^{\circ} \mathrm{C}$ sebesar $0,018 \mathrm{~mol} / \mathrm{gr}$. Jumlah kehilangan $\mathrm{H}_{2} \mathrm{O}$ tersebut ternyata masih lebih rendah dari pelindian dengan perbandingan mol rasio $\mathrm{ZrSiO} / \mathrm{NaOH}(1: 2)$. Hal ini karena jumlah molkul oksigen reaktan dipakai untuk pembentukan produk $\mathrm{Na}_{2} \mathrm{ZrO}_{3}$ dan $\mathrm{Na}_{2} \mathrm{SiO}_{3}$ yang dapat dilihat pada persamaan reaksi (1). Dari perbandingan dengan persamaan reaksi (3) terlihat bahwa walupun jumlah mol $\mathrm{NaOH}$ lebih tinggi dari reaksi (1), tetapi jumlah molkul oksigen dipakai untuk membentuk produk $\mathrm{Na}_{2} \mathrm{ZrO}_{3}$ dan $\mathrm{Na}_{2} \mathrm{SiO}_{3}$. Berdasarkan Lubbe [16] meskipun reaksi (1) diatas tampak stokiometri, tetapi menghasilkan produk padat $\left(\mathrm{Na}_{2} \mathrm{ZrO}_{3}\right.$ dan $\left.\mathrm{Na}_{2} \mathrm{SiO}_{3}\right)$ dan keras. Dengan demikian persamaan reaksi (1) masih menyisakan $\mathrm{ZrSiO}_{4}$ yang tidak bereaksi dengan $\mathrm{NaOH}$, akibatnya jumlah kehilangan $\mathrm{H}_{2} \mathrm{O}$ menjadi lebih kecil dibandingkan dengan reaksi (3).Selanjutnya pada pelindian pada mol rasio $\mathrm{ZrSiO}_{4} / \mathrm{NaOH}$ (1:6) dapat diperlihatkan pada Gambar 5.

Pada Gambar 5, dapat diperlihatkan fenomena lamanya waktu kontak dan tingginya temperatur akan meningkatkan mol kehilangan $\mathrm{H}_{2} \mathrm{O}$. Pada Gambar (5) terlihat bahwa pada mol rasio $\mathrm{ZrSiO} / \mathrm{NaOH}(1: 6)$ kehilangan $\mathrm{H}_{2} \mathrm{O}$ tertinggi dicapai pada waktu kontak 60 menit dengan temperatur $900{ }^{\circ} \mathrm{C}$ sebesar $0,020 \mathrm{~mol} / \mathrm{gr}$. Ternyata hal ini telah terjadi peningkatan mol kehilangan $\mathrm{H}_{2} \mathrm{O}$ dibandingkan dengan mol rasio $\mathrm{ZrSiO}_{4} / \mathrm{NaOH}(1: 4)$, tetapi berharga sama dengan $\mathrm{mol}$ rasio $\mathrm{ZrSiO}_{4} / \mathrm{NaOH}$ (1:2). 


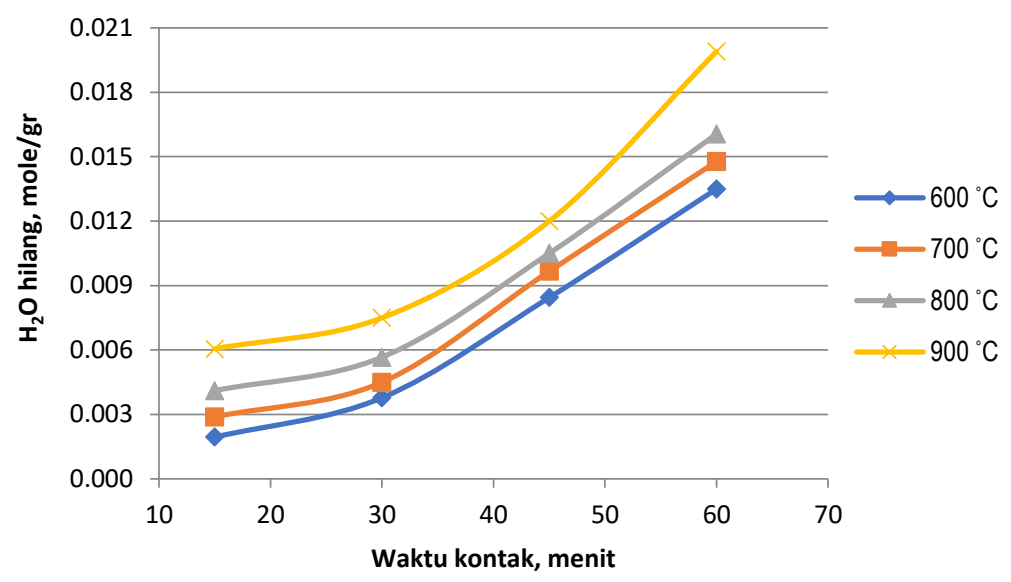

Gambar 5. Perbandingan mol rasio $\mathrm{ZrSiO}_{4} / \mathrm{NaOH}(1: 6)$ pada peleburan zirkon

Fenomena kenaikan mol kehilangan $\mathrm{H}_{2} \mathrm{O}$ dapat dilihat pada persamaan reaksi berikut [14,21]

$$
\mathrm{ZrSiO}_{4}+6 \mathrm{NaOH} \rightarrow \mathrm{Na}_{2} \mathrm{ZrO}_{3}+\mathrm{Na}_{4} \mathrm{SiO} 4+3 \mathrm{H}_{2} \mathrm{O}
$$

Pada persamaan reaksi (4) tersebut walaupun jumlah $\mathrm{mol} \mathrm{NaOH}$ besar, tetapi kenaikan mol kehilangan $\mathrm{H}_{2} \mathrm{O}$ tidak begitu meningkat. Hal ini karena kebutuhan membentuk produk $\mathrm{Na}_{4} \mathrm{SiO}_{4}$ akan membutuhkan lebih banyak $\mathrm{NaOH}$. Pada suasana temperatur tinggi $\left(>600{ }^{\circ} \mathrm{C}\right)$ senyawaan produk $\mathrm{Na}_{4} \mathrm{SiO}_{4}$ tersebut ini sangat dibutuhkan untuk bereaksi dengan $\mathrm{ZrSiO}_{4}$ yang tidak bereaksi selama proses pelindian yang reaksinya [21]

$$
\mathrm{Na}_{4} \mathrm{SiO}_{4}+\mathrm{ZrSiO}_{4} \rightarrow \mathrm{Na}_{2} \mathrm{ZrSiO}_{5}+\mathrm{Na}_{2} \mathrm{SiO}_{3}
$$

Berdasarkan Liu [6], persamaan reaksi no (5) tersebut tidak mudah terjadi bila mineral $\mathrm{ZrSiO}_{4}$ yang digunakan berukuran besar, sehingga untuk memperoleh produk $\mathrm{Na}_{2} \mathrm{ZrO}_{3}$ yang besar sebaiknya partikel mineral tersebut berukuran keci. Partikel berukuran besar mempunyai energi aktivasi yang lebih tinggi, sehingga kontrol pembentukan senyawa $\mathrm{Na}_{2} \mathrm{ZrSiO}_{5}$ biasanya dikontrol dengan ukuran partikel yang optimal.

Selanjutnya bila mol rasio $\mathrm{ZrSiO}_{4} / \mathrm{NaOH}$ dinaikan menjadi (1:8), dengan persamaan reaksi sebagai berikut [14],

$$
\mathrm{ZrSiO}_{4}+8 \mathrm{NaOH} \rightarrow \mathrm{Na}_{4} \mathrm{ZrO}_{4}+\mathrm{Na}_{4} \mathrm{SiO}_{4}+4 \mathrm{H}_{2} \mathrm{O} \uparrow
$$

Pada Gambar 6, telihat bahwa mol kehilangan $\mathrm{H}_{2} \mathrm{O}$ pada pada waktu kontak 60 menit dengan temperatur $900{ }^{\circ} \mathrm{C}$ akan meningkat dibandingkan pada $\mathrm{ZrSiO}_{4} / \mathrm{NaOH}(1: 4)$, yaitu sebesar $0,024 \mathrm{~mol} / \mathrm{gr}$.

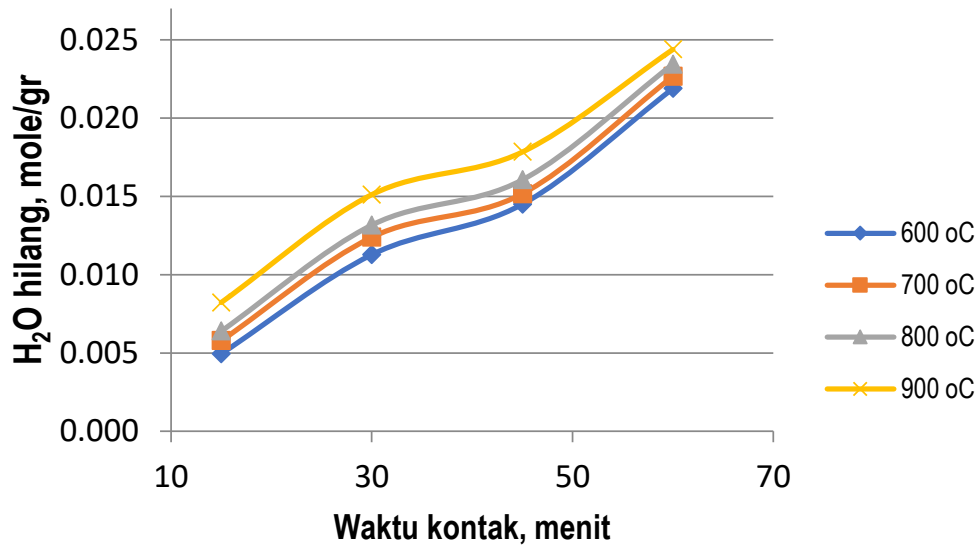

Gambar 6. Perbandingan mol rasio $\mathrm{ZrSiO}_{4} / \mathrm{NaOH}(1: 8)$ pada pelindian zirkon 
Berdasar Biswas [14] kenaikan mol $\mathrm{H}_{2} \mathrm{O}$ yang hilang tersebut karena sumbangan dari reaktan $\mathrm{NaOH}$ yang tidak bereaksi. Hal ini terlihat dengan keadaan struktur produk yang lembab pada hasil pelindian setelah bersentuhan dengan udara pada suhu kamar. Sementara masa leburan yang konstan pada mol rasio $\mathrm{ZrSiO}_{4} / \mathrm{NaOH}(1: 8)$, kemungkinan reaksi peleburan mineral $\mathrm{ZrSiO}_{4}$ dengan $\mathrm{NaOH}$ telah selesai dan meninggalkan sisa $\mathrm{NaOH}$.

$\mathrm{Hal}$ ini ternyata sesuai dengan penelitian Liu [6], bahwa pada suasana $\mathrm{ZrSiO}_{4} / \mathrm{NaOH}(1: 8)$, temperatur $950{ }^{\circ} \mathrm{C}$, fase kristal yang terbentuk di dominasi oleh $\mathrm{Na}_{2} \mathrm{ZrO}_{3}$ dengan tidak dipengaruhi oleh ukuran partikel. Dengan kondisi peleburan tersebut dapat dikatakanbahwa fase kristal $\mathrm{ZrSiO}_{4}$ dan $\mathrm{Na}_{2} \mathrm{ZrSiO}_{5}$ tidak terbentuk.

\section{KESIMPULAN}

Dengan didahului kinerja furnace Nabertherm HT 04/17, ternyata semakin tinggi temperatur dan lama waktu kontak, kehilangan mol $\mathrm{H}_{2} \mathrm{O}$ akan semakin besar. Fenomena ini terjadi di setiap mol rasio $\mathrm{ZrSiO}_{4} / \mathrm{NaOH}$, dan besarnya kehilangan $\mathrm{mol} \mathrm{H}_{2} \mathrm{O}$ akan dipengaruhi oleh stokiometri pelindian atau mol rasio $\mathrm{ZrSiO}_{4} / \mathrm{NaOH}$. Kecuali pada mol rasio $\mathrm{ZrSiO}_{4} / \mathrm{NaOH}(1: 4)$, mol kehilangan $\mathrm{H}_{2} \mathrm{O}$ berharga sama dengan mol rasio $\mathrm{ZrSiO}_{4} / \mathrm{NaOH}$ (1:2). Kehilangan mol $\mathrm{H}_{2} \mathrm{O}$ dicapai pada mol rasio $\mathrm{ZrSiO}_{4} / \mathrm{NaOH}(1: 8)$, pada temperature $950{ }^{\circ} \mathrm{C}$ dan waktu kontak 60 menit sebesar $0,024 \mathrm{~mol} / \mathrm{gr}$. Pada kondisi tersebut sisa fase kristal $\mathrm{ZrSiO}_{4}$ tidak terbentuk, tetapi sampel mengandung sisa $\mathrm{NaOH}$ yang tidak bereaksi dan bersifat pasta.

\section{UCAPAN TERIMA KASIH}

Dengan selesainya pembuatan makalah ini penulis mengucapkan banyak terimakasih kepada Ir. Puradwi I.W, DEA, Suyanti, S.ST dan Ir. Herry Poernomo, MT. Masing-masing sebagai PIt. Kapus PSTA-Batan, Kabid BTP/pembimbing dan Kapok TPZ/pembimbing yang banyak membantu hingga selesainya makalah dengan pendanaan melalui DIPA 2017. Penulis juga sangat berterimakasih kepada saudara Fuad Hanif yang telah banyak membantu di laboratorium.

\section{DAFTAR PUSTAKA}

[1]. H. Poernomo, 'Prospek bisnis pengolahan pasir zirkon lokal menjadi produk zirkonium dan oksida logam tanah jarang bebas radioaktif badan tenaga nuklir nasional', 2014.

[2]. M. M. Zaman et al., 'Presence of uranium and thorium in zircon assemblages separated from beach sands of Cox's Bazar, Bangladesh', J. Sci. Technol. Environ. Informatics, vol. 3, no. 1, pp. 161-169, 2016

[3]. M. A. Coble, S. D. Burgess, and E. W. Klemetti, 'New zircon (U-Th)/He and U/Pb eruption age for the Rockland tephra, western USA', Quat. Sci. Rev., vol. 172, pp. 109-117, 2017.

[4]. P. Boehnke, M. Barboni, and E. A. Bell, 'Zircon U/Th model ages in the presence of melt heterogeneity', Quat. Geochronol., vol. 34, pp. 69-74, 2016.

[5]. M. Danišík, A. K. Schmitt, D. F. Stockli, O. M. Lovera, I. Dunkl, and N. J. Evans, 'Application of combined UTh-disequilibrium/U-Pb and (U-Th)/He zircon dating to tephrochronology', Quat. Geochronol., vol. 40, pp. 23-32, 2017.

[6]. J. Liu, J. Song, T. Qi, C. Zhang, and J. Qu, 'Controlling the formation of Na2ZrSiO5in alkali fusion process for zirconium oxychloride production', Adv. Powder Technol., vol. 27, no. 1, pp. 1-8, 2016.

[7]. E. Zolfonoun, A. B. Monji, M. Taghizadeh, and S. J. Ahmadi, 'Selective and direct sorption of zirconium from acidic leach liquor of zircon concentrate by rice bran', Miner. Eng., vol. 23, no. 9, pp. 755-756, 2010.

[8]. M. Abo-Elmagd, 'Radon exhalation rates corrected for leakage and back diffusion - Evaluation of radon chambers and radon sources with application to ceramic tile', J. Radiat. Res. Appl. Sci., vol. 7, no. 4, pp. 390-398, 2014. 
[9]. V. Moreno, J. Bach, M. Zarroca, L. Font, C. Roqué, and R. Linares, 'Characterization of radon levels in soil and groundwater in the North Maladeta Fault area (Central Pyrenees) and their effects on indoor radon concentration in a thermal spa', J. Environ. Radioact., vol. 189, no. March, pp. 1-13, 2018.

[10]. H. Keramati et al., 'Radon 222 in drinking water resources of Iran: A systematic review, meta-analysis and probabilistic risk assessment (Monte Carlo simulation)', Food Chem. Toxicol., vol. 115, no. January, pp. 460-469, 2018.

[11]. Telahigue, B. Agoubi, F. Souid, and A. Kharroubi, 'Groundwater chemistry and radon-222 distribution in Jerba Island, Tunisia', J. Environ. Radioact., vol. 182, no. November 2017, pp. 74-84, 2018.

[12]. L. H. Gevantman, 'Solubility of Selected Gases in Water', CRC Handb. Chem. Phys., pp. 5-8, 2015.

[13]. N. Vogeltanz-Holm and G. G. Schwartz, 'Radon and lung cancer: What does the public really know?', J. Environ. Radioact., vol. 192, no. January, pp. 26-31, 2018.

[14]. R. K. Biswas, M. A. Habib, A. K. Karmakar, and M. R. Islam, 'A novel method for processing of Bangladeshi zircon: Part I: Baking, and fusion with NaOH', Hydrometallurgy, vol. 103, no. 1-4, pp. 124-129, 2010.

[15]. R. J. F. Da Silva, A. J. B. Dutra, and J. C. Afonso, 'Alkali fusion followed by a two-step leaching of a Brazilian zircon concentrate', Hydrometallurgy, vol. 117-118, pp. 93-100, 2012.

[16]. S. Lubbe, R. Munsami, and D. Fourie, 'Beneficiation of zircon sand in South Africa', J. South. African Inst. Min. Metall., vol. 112, no. 7, pp. 583-588, 2012.

[17]. N. Van Tuyen, V. T. Quang, T. G. Huong, and V. H. Anh, 'Preparation of High Quality Zirconium', VAECAnual Rep., vol. 7, no. 43, pp. 286-291, 2007.

[18]. D. . Aminhar, 'Kalibrasi muffle furnace', Urania, vol. VI, no. 21-22, pp. 9-13, 2000.

[19]. A. Kaiser, M. Lobert, and R. Telle, 'Thermal stability of zircon (ZrSiO4)', J. Eur. Ceram. Soc., vol. 28, no. 11, pp. 2199-2211, 2008.

[20]. A. M. Abdel-Rehim, 'A new technique for extracting zirconium form Egyptian zircon concentrate', Int. J. Miner. Process., vol. 76, no. 4, pp. 234-243, 2005.

[21]. C. Yamagata, J. B. Andrade, V. Ussui, N. B. de Lima, and J. O. A. Paschoal, 'High Purity Zirconia and Silica Powders via Wet Process: Alkali Fusion of Zircon Sand', Mater. Sci. Forum, vol. 591-593, pp. 771-776, 2008. 